\title{
Níveis de Energia na Dieta para Bubalinos em Crescimento Alimentados em Confinamento. 2. Características da Carcaça ${ }^{1}$
}

\author{
Raul Franzolin², Juliano Roberto da Silva ${ }^{3}$
}

\begin{abstract}
RESUMO - Quinze bubalinos em crescimento da raça Mediterrâneo foram alimentados em confinamento por aproximadamente 140 dias com o objetivo de avaliar os efeitos de três níveis de energia ingerida sobre as características de carcaça. Os animais foram abatidos quando atingiram peso vivo acima de $450 \mathrm{~kg}$. As ingestões médias de energia metabolizável estimadas para os três tratamentos foram: $18,23,19,54$ e 21,74 Mcal/animal/dia. O peso médio de abate foi de $465 \mathrm{~kg}+/-16,29 \mathrm{~kg}$. Não houve diferenças significativas entre os tratamentos nos rendimentos de carcaça quente e fria (médias de 51,27 e 50,30\%, respectivamente) e nos rendimentos dos cortes primários e secundários da carcaça, exceto para o coxão completo, que apresentou menor rendimento no nível médio de energia ingerida. Concluiu-se que não houve evidências de existirem diferenças nos rendimentos da carcaça e de seus cortes primários e secundários entre bubalinos consumindo três diferentes níveis de energia e que os bubalinos mostraram apresentar bom potencial de produção de carcaça e cortes comerciais nessas condições.
\end{abstract}

Palavras-chave: bubalino, carcaça, confinamento, energia

\section{Energy Levels in the Diet for Growing Buffaloes under Feedlot. 2. Carcass Characteristics}

\begin{abstract}
Fifteen growing buffaloes of the Mediterranean breed were fed in feedlot for aproximately 140 days with the objective to evaluate three different levels of energy ingested on carcass characteristics. The animals were slaughtered when they reached body weight above $450 \mathrm{~kg}$. The average body weight was $465 \mathrm{~kg}+/-16.29 \mathrm{~kg}$. The average metabolizable energy intake estimated for the three treatments were: $18.23,19.54$ and $21.74 \mathrm{Mcal} /$ animal/day. There were no significant differences among treatments in the hot and cold dressing carcass (averages 51.27 and $50.30 \%$, respectively) and carcass primary and secondary cut percentages, except for whole round that presented lower percentage in the intermediary level of energy ingested. It was concluded that there were no evidences of differences in the dressing carcass and of its primary and secondary cuts among buffaloes with three different levels of energy intake and that buffalo showed potential of carcass production with commercial cuts when fed in feedlot.
\end{abstract}

Key Words: buffaloes, carcass, energy, feedlot

\section{Introdução}

Para um desempenho animal eficiente, há necessidade de conhecimentos básicos da nutrição de bubalinos. CHALMERS (1974) enfatizou a grande importância de se desenvolver estudos mais detalhados da fisiologia nutricional do bubalino, incluindo dados básicos sobre o metabolismo dos nutrientes, exigências nutritivas, avaliação corporal e outros. Porém, ainda há escassez de informações sobre requerimentos de nutrientes para os bubalinos, especialmente nas nossas condições. Assim, dados obtidos com bovinos têm sido extrapolados para bubalinos, resultando em considerável ineficiência alimentar.

As formulações modernas de rações para ruminantes baseiam-se em cálculos feitos a partir da concentração energética da ração e da demanda de nitrogênio pelos microrganismos no rúmen para síntese de proteína microbiana (AGRICULTURAL RESEARCH COUNCIL - ARC, 1980). O metabolismo ruminal depende, portanto, da concentração energética da dieta que influi na retenção de nutrientes e nas características da carcaça.

Vários fatores afetam o rendimento de carcaça e a composição corporal: genética, idade, sexo, nutrição e alimentação etc. Entre eles, o nível energético da dieta consumida apresenta-se de grande importância, já que a deposição de gordura corporal promove diferenças na quantidade e qualidade da carcaça produzida. KEARL (1982) recomenda para mantença de bubalinos o valor médio de $125 \mathrm{kcal}$ de energia metabolizável $/ \mathrm{kg} \mathrm{PV}^{0,75} /$ dia e $10 \mathrm{kcal}$ de $\mathrm{EM} / \mathrm{g}$ de

\footnotetext{
1 Trabalho financiado pela FAPESP.

${ }_{2}^{2}$ Professor Titular do Departamento de Zootecnia da FZEA/USP - Campus da USP, 13695-900 - Pirassununga - SP. E.mail: rfranzol@usp.br

${ }^{3}$ Bolsista de Iniciação Científica do PIBIC/CNPq.
} 
ganho para animais até $250 \mathrm{~kg}$ e mais $0,02 \mathrm{kcal} / \mathrm{kg}$ de peso acima de $250 \mathrm{~kg} / \mathrm{g}$ de ganho. JORGE et al. (1997c) observaram rendimento médio de carcaça de 49,44\% em bubalinos abatidos em diferentes estádios de maturidade alimentados com dieta contendo 2,4 Mcal de EM/kg MS com diferenças na composição da carcaça entre bubalinos e bovinos, refletindo diferenças no metabolismo animal dessas espécies. OLIVEIRA et. al. (1991) verificaram, em bubalinos sob confinamento, rendimento médio de 49,30\%, também com diferenças na composição corporal entre bubalinos e zebuínos. AFIF et al. (1974) observaram rendimento médio de carcaça de 50 a $55 \%$ para bubalinos machos com diferentes pesos e idade de abate. VELLOSO et al. (1994) observaram rendimento de carcaça quente médio de $49,2 \%$ em bubalinos alimentados em 112 dias de confinamento com cana-de-açúcar ad libitum, farinha de mandioca e farelo de soja.

Alguns trabalhos têm sido realizados comparando-se bubalinos com bovinos com o objetivo de obterse dados sobre os rendimentos e as características das carcaças como animais produtores comerciais de carne, alimentados em regime de confinamento e em pastagem. JORGE et al. (1997a) avaliaram o rendimento de cortes comerciais em bubalinos da raça mediterrâneo comparativamente com bovinos da raça Nelore terminados em confinamento recebendo ração ad libitum constituída de $60 \%$ de silagem de milho e $40 \%$ de concentrado. Os autores verificaram que os bubalinos apresentaram maiores rendimentos dos cortes de contra-filé, filé mignon, alcatra, coxão duro e músculo do traseiro enquanto que os nelores apresentaram maiores rendimentos de coxão mole, capa e aba e ossos do serrote. MATTOS et al. (1997) também avaliaram as características da carcaça de bubalinos e bovinos nessas mesmas condições e observaram semelhanças nos rendimentos dos principais cortes primários da carcaça entre ambas espécies animais estudadas. MULLER et al. (1994) observaram rendimento médio de carcaça de 53,09\% em bubalinos mediterrâneos em pastagem abatidos aos 24 meses de idade. Já, MACEDO et al. (2000a) verificaram menores rendimentos de carcaça quente para bubalinos em pastagem com idades médias de 24 meses $(45,24 \%)$ e de 48 meses $(49,85 \%)$. MATTOS et al. (1998) avaliaram os pesos de abate, de carcaça e seus cortes primários e secundários em bubalinos machos inteiros, machos castrados e fêmeas, todos criados em pastagens. Os autores observa- ram pesos mais elevados da carcaça quente e fria e na maioria dos cortes cárneos estudados nos machos castrados que nos machos inteiros e nas fêmeas. MACEDO et al. (2000b) observaram rendimento de carcaça quente de 50,81\% para bubalinos não castrados e de 51,53\% para castrados terminados em confinamento, enquanto que para animais em regime de pastagem os rendimentos foram de 48,91\% e $49,19 \%$ para animais não castrados e castrados, respectivamente. Segundo JORGE et al. (1997b) o peso de abate influencia o ganho médio diário de peso corporal vazio e o ganho médio diário de carcaça, porém, não influencia a conversão alimentar em bubalinos e bovinos. O objetivo deste trabalho foi o de avaliar as características de carcaça de bubalinos alimentados em confinamento em três níveis diferentes de energia.

\section{Material e Métodos}

Três grupos de cinco bubalinos inteiros, com peso médio inicial de $330 \mathrm{~kg}$ e idade média de 498 dias foram utilizados em um experimento inteiramente casualizado com alimentação em confinamento. Durante as primeiras 4 semanas, eles permaneceram em período de adaptação às instalações e ao manejo geral, recebendo dieta de feno de capim-coastcross (Cynodon dactylon) à vontade mais $1 \mathrm{~kg}$ de concentrado por animal/dia.

Os tratamentos consistiram de três diferentes níveis de ingestão de energia: BE (baixa energia), RE (requerida energia) e AE (alta energia). RE foi calculado de acordo com o requerimento diário de energia para mantença de bubalinos em crescimento de $125 \mathrm{kcal} \mathrm{EM} / \mathrm{kg}^{0,75}$. O nível BE com $20 \%$ abaixo do nível de mantença e o AE com $20 \%$ acima. Para estimativa do requerimento energético para ganho de peso, adotou-se um ganho médio diário de $800 \mathrm{~g}$, correspondendo a $10 \mathrm{kcal}$ de EM para animais até $250 \mathrm{~kg}$ e mais $0,02 \mathrm{kcal} / \mathrm{kg}$ de peso acima de $250 \mathrm{~kg} / \mathrm{g}$ de ganho, conforme recomendações de KEARL (1982).

As rações foram formuladas com feno de capim-coastcross, como volumoso, e milho em grão moído e farelo de soja, como concentrado. Os níveis de energia metabolizável consumidos foram calculados de acordo com os teores médios de EM dos ingredientes citados para bubalinos por KEARL (1982) e apresentados na Tabela 1. Amostras dos ingredientes foram colhidas durante todo o período experimental e determinadas as suas composições 
bromatológicas. A fim de se obter o máximo controle possível da quantidade de energia ingerida pelo animal de acordo com os níveis de energia dos tratamentos, foram utilizados 3 níveis de concentração energética na ração: baixo, médio e alto, mantendose o nível de concentrado em $60 \%$, no máximo. A cada 3 semanas, as rações foram recalculadas em função do novo peso do animal, aumentando-se a quantidade da dieta ou a concentração energética da ração, para garantir o nível de ingestão de energia desejável. A quantidade diária total das rações foi oferecida dividida em duas partes iguais. De

Tabela 1 - Composições bromatológicas dos ingredientes utilizados nas rações (\% na matéria seca)

Table 1 - Proximal analyses of feedstuffs rations (\% on dry matter basis)

\begin{tabular}{|c|c|c|c|}
\hline \multirow[t]{2}{*}{ Itens } & \multicolumn{3}{|c|}{$\begin{array}{c}\text { Ingredientes } \\
\text { Feedstuffs }\end{array}$} \\
\hline & $\begin{array}{l}\text { eno de capim- } \\
\text { coastcross } \\
\text { Coastcross } \\
\text { grass hay }\end{array}$ & $\begin{array}{l}\text { Farelo de } \\
\text { soja } \\
\text { Soybean } \\
\text { meal }\end{array}$ & $\begin{array}{l}\text { Milho } \\
\text { grãos } \\
\text { Corn } \\
\text { grain }\end{array}$ \\
\hline $\begin{array}{l}\text { Matéria seca } \\
\text { Dry matter }\end{array}$ & 90,54 & 88,04 & 86,67 \\
\hline $\begin{array}{l}\text { Proteína bruta } \\
\text { Crude protein }\end{array}$ & 6,26 & 50,99 & 10,07 \\
\hline $\begin{array}{l}\text { Fibra bruta } \\
\text { Crude fiber }\end{array}$ & 33,32 & 6,52 & 1,95 \\
\hline $\begin{array}{l}\text { Extrato etéreo } \\
\text { Ether extract }\end{array}$ & 1,23 & 1,66 & 3,52 \\
\hline $\begin{array}{l}\text { Extrativos não } \\
\text { nitrogenados } \\
\text { Free nitrogen extracts }\end{array}$ & 53,94 & 33,75 & 83,00 \\
\hline $\begin{array}{l}\text { Matéria mineral } \\
\text { Mineral matter }\end{array}$ & 5,25 & 7,09 & 1,45 \\
\hline $\begin{array}{l}\text { Cálcio } \\
\text { Calcium }\end{array}$ & 0,39 & 0,34 & 0,06 \\
\hline $\begin{array}{l}\text { Fósforo } \\
\text { Phosphorus }\end{array}$ & 0,13 & 0,56 & 0,13 \\
\hline $\begin{array}{l}\text { FDN } \\
N D F\end{array}$ & 75,56 & - & - \\
\hline $\begin{array}{l}\text { FDA } \\
A D F\end{array}$ & 39,61 & - & - \\
\hline $\begin{array}{l}\text { Celulose } \\
\text { Cellulose }\end{array}$ & 35,69 & - & - \\
\hline $\begin{array}{l}\text { Lignina } \\
\text { Lignin }\end{array}$ & 7,00 & - & - \\
\hline $\begin{array}{l}\text { Energia bruta } \\
\text { (Mcal/kg MS) } \\
\text { Crude energy } \\
\text { (Mcal/kg DM) }\end{array}$ & 4,131 & 4,426 & 3,881 \\
\hline $\begin{array}{l}\text { Energia metabolizável } \\
\text { (Mcal/kg MS) } \\
\text { Metabolize energy }^{1}\end{array}$ & 1,97 & 3,17 & 3,19 \\
\hline
\end{tabular}

manhã, pesavam-se as sobras de cada baia, fornecendo-se, em seguida, o concentrado e aproximadamente 40 minutos após, colocava-se o feno. Os animais tiveram livre acesso a uma mistura completa de sal mineral e água através de bebedouros automáticos.

Ao atingirem o peso estipulado acima de $450 \mathrm{~kg}$, os animais foram abatidos para avaliação de carcaça, no matadouro do Campus de Pirassununga da USP, seguindo-se todos os procedimentos adequados de higiene. O peso vivo de abate foi obtido após pesagem dos animais em dieta hídrica por período mínimo de 12 horas. Após o preparo comercial das carcaças, elas foram lavadas em água corrente e pesadas, obtendo-se os pesos das carcaças quentes, seguindo-se para uma câmara fria, onde permaneceram por 24 horas, sendo pesadas novamente, obtendo-se os pesos das carcaças frias. Em seguida, as carcaças foram separadas na $5^{\text {a }}$ costela em dianteiro, traseiro e ponta de agulha e posteriormente em cortes primários e secundários, pesando-se individualmente, cada peça obtida. O peso corporal vazio foi obtido subtraindo-se o peso do conteúdo gastrintestinal do peso vivo de abate.

Os dados obtidos foram analisados estatisticamente por computação pela análise de variância para experimento inteiramente aleatório (ZAR, 1984) com o cálculo da estatística $F$ e de seu respectivo “p-value". Nos casos em que $p<0,05$, as médias dos tratamentos foram comparadas pelo teste de Tukey.

As análises foram desenvolvidas em computador no Centro de Computação da Faculdade de Medicina Veterinária e Zootecnia da UNESP, Campus de Botucatu e com o uso de programa de estatística (STATSOFT, 1995).

\section{Resultados e Discussão}

As ingestões médias de energia metabolizável estimadas para os três tratamentos foram: 18,23 (BE), 19,54 (RE) e 21,74 (AE) Mcal/animal/dia.

Na Tabela 2 estão apresentados os dados médios obtidos dos pesos de abate e corporal vazio dos bubalinos e das carcaças, bem como, os rendimentos das carcaças quente e fria. Os bubalinos apresentaram peso médio de abate de $465 \mathrm{~kg}+/-16,29$. Não houve diferenças significativas $(\mathrm{P}>0,05)$ nos rendimentos das carcaças quente e fria obtidos entre os bubalinos com diferentes níveis de energia consumida que foram em média de 51,27 e 50,30\%, respectiva- 
Tabela 2 - Rendimento da carcaça de bubalinos em confinamento sob dieta com três níveis diferentes de energia Table 2 - Carcass dressing of fedlot buffaloes fed diets with three different levels of energy

\begin{tabular}{|c|c|c|c|c|c|c|}
\hline & \multicolumn{3}{|c|}{$\begin{array}{l}\text { Nível de energia } \\
\text { Energy level }\end{array}$} & \multirow[b]{2}{*}{$\begin{array}{l}\text { Média } \\
\text { Mean }\end{array}$} & \multirow[b]{2}{*}{$\begin{array}{l}\mathrm{DP}^{1} \\
S D^{1}\end{array}$} & \multirow[b]{2}{*}{$\begin{array}{l}\mathrm{EPM}^{2} \\
S E M^{2}\end{array}$} \\
\hline & $\begin{array}{c}\text { Baixa (BE) } \\
\text { Low }(L E)\end{array}$ & $\begin{array}{c}\text { Requerida }(\mathrm{RE}) \\
\text { Required }(R E)\end{array}$ & $\begin{array}{l}\text { Alta (AE) } \\
\text { High }(H E)\end{array}$ & & & \\
\hline $\begin{array}{l}\text { PA }(\mathrm{kg})^{3} \\
S W(\mathrm{~kg})^{3}\end{array}$ & 462,40 & 459,00 & 473,60 & 465,00 & 16,29 & 4,21 \\
\hline $\begin{array}{l}\operatorname{PCV~}(\mathrm{kg})^{4} \\
E B W(\mathrm{~kg})^{4}\end{array}$ & 427,74 & 423,04 & 438,42 & 429,73 & 15,40 & 3,98 \\
\hline $\begin{array}{l}\text { PCQ }(\mathrm{kg})^{5} \\
H C W(\mathrm{~kg})^{5}\end{array}$ & 235,30 & 235,60 & 244,20 & 238,37 & 9,14 & 2,36 \\
\hline $\begin{array}{l}\operatorname{PCF}(\mathrm{kg})^{6} \\
C C W(\mathrm{~kg})^{6}\end{array}$ & 231,00 & 230,20 & 240,40 & 233,87 & 9,22 & 2,38 \\
\hline $\begin{array}{l}\text { Quebra }(\%)^{7} \\
\text { Chilling loss }(\%)^{7}\end{array}$ & 1,82 & 2,28 & 1,56 & 1,89 & 0,61 & 0,16 \\
\hline $\begin{array}{l}\mathrm{RCQ}(\%)^{8} \\
H C D(\%)^{8}\end{array}$ & 50,88 & 51,37 & 51,57 & 51,27 & 1,31 & 0,34 \\
\hline $\begin{array}{l}\operatorname{RCF}(\%)^{9} \\
C C D(\%)^{9}\end{array}$ & 49,96 & 50,19 & 50,76 & 50,30 & 1,33 & 0,34 \\
\hline
\end{tabular}

Não foram observadas diferences significativas entre os valores $(P>0,05)$.

$1 \mathrm{DP}=$ desvio-padrão da média; ${ }^{2} \mathrm{EPM}=$ erro-padrão da média $;{ }^{3} \mathrm{PA}=$ peso de abate; ${ }^{4} \mathrm{PCV}=$ peso corporal vazio; ${ }^{5} \mathrm{PCQ}=$ peso da carcaça quente;

${ }^{6} \mathrm{PCF}=$ peso da carcaça fria; ${ }^{7}$ Quebra $=\mathrm{PCQ}-\mathrm{PCF} / 100 ;{ }^{8} \mathrm{RCQ}=$ rendimento de carcaça quente em relação ao $\mathrm{PA} ;{ }^{9} \mathrm{RCF}=$ rendimento de carcaça fria em relação ao PA.

No significant differences were observed among the values $(P>.05)$.

${ }^{1} \mathrm{SD}=$ standard deviation; ${ }^{2} \mathrm{SEM}=$ standard error mean; ${ }^{3} \mathrm{SW}=$ slaughter weight; ${ }^{4} \mathrm{EBW}=$ empty body weight; ${ }^{5} \mathrm{HCW}=$ hot carcass weight; ${ }^{6} \mathrm{CCW}=\mathrm{cold}$ carcass weight;

7 Chilling loss $=\mathrm{HCW}-\mathrm{CCW} / 100 ;{ }^{8} \mathrm{HCD}=$ hot carcass dressing in relation to the $S W ;{ }^{9} \mathrm{CCD}=$ cold carcass dressing in relation to the $\mathrm{SW}$.

mente. O rendimento de carcaça quente obtido foi superior aos encontrados por OLIVEIRA et. al. (1991), JORGE et. al. (1997c), VELLOSO et al. (1994) e MACEDO et al. (2000a) para bubalinos não castrados alimentados em regime de confinamento e concorda com AFIF et al. (1974) que observaram rendimento médio de carcaça de 50 a $55 \%$ para bubalinos machos com diferentes pesos e idade de abate. MULLER et al. (1994) verificaram rendimento de carcaça superior $(53,09 \%)$ e MACEDO et al. (2000b) obtiveram rendimento inferior $(48,91 \%)$ para bubalinos em pastagem.

Os rendimentos dos cortes primários da carcaça dos bubalinos podem ser vistos na Tabela 3 . Não foram detectadas diferenças significativas $(\mathrm{P}>0,05)$ entre os tratamentos nos rendimentos médios dos componentes primários da carcaça, exceto para o coxão completo que apresentou menor rendimento em RE. Os rendimentos obtidos dos cortes primários estão próximos aos observados por MATTOS et al. (1997), JORGE et al. (1997a) e JORGE et al. (1997c) com bubalinos em confinamento, porém os bubalinos apresentaram maior rendimento médio de coxão completo e menor de alcatra completa em relação aos obtidos por JORGE et al. (1997c). Foi notada maior deposição aparente de gordura na ponta de agulha com nível alto de energia, o que deve ter contribuído para uma tendência de aumento crescente no peso da costela observado nos animais alimentados com níveis maiores de energia. De fato, BARUAH et al. (1988) observaram maiores porcentagens de gordura na carcaça em bubalinos alimentados com rações contendo níveis mais altos de energia.

Os rendimentos dos cortes secundários da carcaça dos bubalinos sob ingestão de três níveis de energia encontram-se na Tabela 4. Não houve diferenças significativas $(\mathrm{P}>0,05)$ nos rendimentos dos cortes secundários das carcaças entre os tratamentos. Observou-se apenas uma tendência $(\mathrm{P}<0,10)$ para os animais com dietas alta em energia apresentarem menor rendimento do filé mignon e maior de costela. 
Tabela 3 - Rendimentos (\%) dos cortes primários da carcaça de bubalinos em confinamento alimentados com dietas com três níveis diferentes de energia

Table 3 - Carcass percentage of primary cuts of fedlot buffaloes fed diets with three different levels of energy

\begin{tabular}{|c|c|c|c|c|c|c|}
\hline & \multicolumn{3}{|c|}{$\begin{array}{c}\text { Nível de energia } \\
\text { Energy level }\end{array}$} & \multirow[b]{2}{*}{$\begin{array}{l}\text { Média } \\
\text { Mean }\end{array}$} & \multirow[b]{2}{*}{$\begin{array}{l}\mathrm{DP} \\
S D^{1}\end{array}$} & \multirow[b]{2}{*}{$\begin{array}{l}\mathrm{EPM}^{2} \\
S E M^{2} \\
\end{array}$} \\
\hline & $\begin{array}{c}\text { Baixa }(\mathrm{BE}) \\
\text { Low }(L E)\end{array}$ & $\begin{array}{c}\text { Requerida(RE) } \\
\text { Required (RE) }\end{array}$ & $\begin{array}{l}\text { Alta (AE) } \\
\operatorname{High}(H E)\end{array}$ & & & \\
\hline $\begin{array}{l}\text { Dianteiro } \\
\text { Hindquarter }\end{array}$ & 38,74 & 39,06 & 37,53 & 38,44 & 1,53 & 0,39 \\
\hline $\begin{array}{l}\text { Traseiro } \\
\text { Forequarter }\end{array}$ & 61,26 & 60,94 & 62,47 & 61,56 & 1,53 & 0,39 \\
\hline $\begin{array}{l}\text { Paleta completa } \\
\text { Whole shoulder }\end{array}$ & 17,43 & 17,34 & 16,61 & 17,13 & 0,90 & 0,23 \\
\hline $\begin{array}{l}\text { Acém completo } \\
\text { Whole shoulder blade }\end{array}$ & 21,31 & 21,71 & 20,91 & 21,31 & 0,91 & 0,24 \\
\hline $\begin{array}{l}\text { Ponta de agulha } \\
\text { Spare ribs }\end{array}$ & 13,44 & 13,79 & 15,14 & 14,12 & 1,86 & 0,48 \\
\hline $\begin{array}{l}\text { Alcatra completa } \\
\text { Whole rump }\end{array}$ & 14,59 & 15,50 & 14,95 & 15,02 & 1,07 & 0,28 \\
\hline $\begin{array}{l}\text { Coxão completo } \\
\text { Whole round }\end{array}$ & $33,22^{\mathrm{a}}$ & $31,65^{b}$ & $32,38^{a b}$ & 32,42 & 1,16 & 0,30 \\
\hline
\end{tabular}

Tabela 4 - Rendimentos (\%) dos cortes secundários da carcaça de bubalinos em confinamento alimentados com dietas com três níveis diferentes de energia

Table 4 - Carcass percentage of secondary cuts of fedlot buffaloes fed diets with three different levels of energy

\begin{tabular}{|c|c|c|c|c|c|c|}
\hline & \multicolumn{3}{|c|}{$\begin{array}{c}\text { Nível de energia } \\
\text { Energy level }\end{array}$} & \multirow[b]{2}{*}{$\begin{array}{l}\text { Média } \\
\text { Mean }\end{array}$} & \multirow[b]{2}{*}{$\begin{array}{l}\mathrm{DP}^{1} \\
S D^{1}\end{array}$} & \multirow[b]{2}{*}{$\begin{array}{l}\mathrm{EPM}^{2} \\
S E M^{2}\end{array}$} \\
\hline & $\begin{array}{c}\text { Baixa (BE) } \\
\text { Low }(L E)\end{array}$ & $\begin{array}{c}\text { Requerida }(\mathrm{RE}) \\
\text { Required }(R E)\end{array}$ & $\begin{array}{l}\text { Alta (AE) } \\
\operatorname{High}(H E)\end{array}$ & & & \\
\hline Paleta (Shoulder) & 9,91 & 10,16 & 10,00 & 10,02 & 0,54 & 0,14 \\
\hline Acém (Chuck roll) & 5,78 & 5,81 & 5,86 & 5,81 & 0,55 & 0,14 \\
\hline Fraldinha (Fraudinha) & 2,16 & 1,95 & 2,10 & 2,07 & 0,28 & 0,07 \\
\hline Costela (Rib) & 7,11 & 8,68 & 8,78 & 8,19 & 1,43 & 0,37 \\
\hline Ponta de peito (Brisket) & 2,83 & 2,70 & 2,58 & 2,71 & 0,32 & 0,08 \\
\hline Pescoço (Neck) & 2,73 & 3,00 & 2,90 & 2,88 & 0,31 & 0,08 \\
\hline Flanco (Flank) & 0,58 & 0,49 & 0,52 & 0,53 & 0,10 & 0,03 \\
\hline Filé mignon (Filet mignon) & 1,58 & 1,57 & 1,44 & 1,53 & 0,13 & 0,03 \\
\hline Contra-filé (Contra-filet) & 5,09 & 5,10 & 4,93 & 5,04 & 0,30 & 0,08 \\
\hline Capa de filé (Capa de filet) & 0,50 & 0,50 & 0,52 & 0,50 & 0,08 & 0,21 \\
\hline Alcatra (Rump) & 3,57 & 3,36 & 3,45 & 3,46 & 0,21 & 0,06 \\
\hline Picanha (Picanha) & 1,63 & 1,55 & 1,57 & 1,58 & 0,14 & 0,03 \\
\hline Coxão mole (Soft round) & 6,03 & 5,88 & 5,75 & 5,88 & 0,32 & 0,08 \\
\hline Coxão duro (Hard round) & 4,45 & 4,01 & 4,08 & 4,18 & 0,48 & 0,12 \\
\hline Patinho (Patinho) & 3,83 & 3,73 & 3,71 & 3,76 & 0,21 & 0,05 \\
\hline Lagarto (Lagarto) & 2,15 & 1,76 & 1,76 & 1,89 & 0,45 & 0,12 \\
\hline Músculo Paleta (Shoulder muscle) & 2,16 & 2,22 & 1,91 & 2,10 & 0,34 & 0,09 \\
\hline Músculo Coxão (Round muscle) & 3,02 & 2,87 & 2,99 & 2,96 & 0,31 & 0,08 \\
\hline
\end{tabular}

1 d.p. - Desvio-padrão da média geral; ${ }^{2}$ e.p.m. - Erro-padrão da média.

1 SD = Standard deviation; ${ }^{2}$ SEM = Standard error mean; Standard error of mean.

Valores com de letras diferentes na mesma linha diferem significativamente $(P<0,05)$.

Values followed by different letters in same line are different by Tukey test $(P<0.05)$.

Valores com ausências de letras na mesma linha não diferem significativamente $(P>0,05)$

Values with no letters in same line are not different by Tukey test $(P<0.05)$.

Não foram observadas diferences significativas entre os valores $(P>0,05)$.

No significant differences were observed among the values $(P>$.05). 


\section{Conclusões}

Não houve evidências de existirem diferenças nos rendimentos da carcaça e de seus cortes primários e secundários entre bubalinos consumindo três diferentes níveis de energia.

Os bubalinos mostrararam apresentar potencial de produção de carcaça com bons rendimentos de cortes comerciais quando alimentados em regime de confinamento.

\section{Agradecimento}

À Fundação de Amparo a Pesquisa do Estado de São Paulo (FAPESP), pelo apoio financeiro a este trabalho de pesquisa.

Ao Prof. Dr. Paulo Cury da Faculdade de Medicina Veterinária e Zootecnia da UNESP, Campus de Botucatu, pelo apoio nas análises estatísticas do trabalho.

\section{Referências Bibliográficas}

AFIF, Y.A, SHAHIN, M.A., OMARA, S.F. et al. 1974. Meat production from buffalo male calves at different ages. Agricultural Research Review, 52:1-20.

AGRICULTURAL RESEARCH COUNCIL - ARC. 1980. The nutrient requirements of ruminant livestock. London: CAB. $351 \mathrm{p}$.

BARUAH, K.K., RANJHAN, S.K., PATHAK, N.N. 1988. Influence of dietary protein and energy on carcass characteristics of male buffalo calves. In: WORLD BUFFALO CONGRESS, 2, 1988, New Delhi. Proceedings...New Delhi:IBF, p.202. 1988.

CHALMERS, M.I. 1974. Nutrition. In: COCKRILL, W.R. 1974. The husdandry and health of the domestic buffalo. Rome: FAO. p.167-194.

JORGE, A.M., MATTOS, J.C.A., NOGUEIRA, J.R. Rendimentos de cortes comerciais da carcaça de bubalinos e de bovinos terminados em confinamento. In: REUNIÃO ANUAL DA SOCIEDADE BRASILEIRA DE ZOOTECNIA, 34, 1997a, Juiz de Fora. Anais... Juiz de Fora: SBZ, 1997a. p.323-325.

JORGE, A.M., FONTES, C.A.A., FREITAS, J.A. et al. 1997b. Ganho de peso e de carcaça, consumo e conversão alimentar de bovinos e bubalinos, abatidos em dois estádios de maturidade. Rev. bras. zootec., 26(4):806-812.

JORGE, A.M., FONTES, C.A.A., FREITAS, J.A. et al. 1997c. Rendimento de carcaça e de cortes básicos de bovinos e bubalinos, abatidos em diferentes estádios de maturidade. Rev. bras. zootec., 26(5):1048-1054.
KEARL, L.C. 1982. Nutrient requirements of ruminant in development contries. Logan: Utah State University. 381p.

MACEDO, M.P., BIANCHINI SOBRINHO, E., KAWATOKU, M. et al. Efeito da descorna sobre as características de carcaça de bubalinos da raça mediterrâneo abatidos em diferentes estágios de maturidade. In: REUNIÃO ANUAL DA SOCIEDADE BRASILEIRA DE ZOOTECNIA, 37, 2000a, Viçosa. Anais...Viçosa:SBZ, 2000a. p.1-3.

MACEDO, M.P., BIANCHINI SOBRINHO, E., RESENDE, F.D. et al. Características de carcaça de bubalinos da raça mediterrâneo terminados em diferentes regimes alimentares. In: REUNIÃO ANUAL DA SOCIEDADE BRASILEIRA DE ZOOTECNIA, 37, 2000b, Viçosa. Anais...Viçosa:SBZ, 2000b. p.1-3.

MATTOS, J.C.A., JORGE, A.M., NOGUEIRA, J.R. Características da carcaça de bubalinos mediterrâneo (Bubalus bubalis) e bovinos nelore (Bos indicus) terminados em confinamento. In: REUNIÃO ANUAL DA SOCIEDADE BRASILEIRA DE ZOOTECNIA, 34, 1997, Juiz de Fora. Anais...Juiz de Fora:SBZ, 1997. p.346-348.

MATTOS, J.C.A., KAWATOKO, M., SCHAMMASS, E.A. et al. Medições no abate e desossa e avaliação da qualidade de carne de bubalinos machos inteiros, castrados e fêmeas. In: REUNIÃO ANUAL DA SOCIEDADE BRASILEIRA DE ZOOTECNIA, 35, 1998, Botucatu. Anais...Botucatu:SBZ, 1998. p.88-90.

MULLER, L., AGUIRRE, L.F., RESTLE, J. et al. Carcass and meat quality of cattle and buffalo. In: WORLD BUFFALO CONGRESS, 4, 1994, São Paulo. Proceedings... São Paulo: ABCB, 1994. v.2, p.130-132.

OLIVEIRA, A.L., VELLOSO, L., SCHALCH, E. 1991. Carcass characteristics and yield of zebu steers compared with water buffalo. In: WORLD BUFFALO CONGRESS, 3, 1991, In: WORLD BUFFALO CONGRESS, 2, 1988, Varna. Proceedings...Varna: IBF, 1991. p.1019-1026.

STATSOFT, INC. 1995. Statistica for windows [computer program manual]. Tulsa.

VELlOSO, L., SCHALCH, E., ZANETTI, M.A. et al. Comparative performance of buffalo, zebu (Nelore) and Holstein steers, fed crude soybean meal, dry cassava meal and ground sugar-cane in feedlot trial. In: WORLD BUFFALO CONGRESS, 4, 1994, São Paulo. Proceedings... São Paulo: ABCB, 1994. v.2, p.266-268.

ZAR, J.H. 1984. Biostatistical analysis. 2.ed. Englewood Cliffs: Prentice Hall. 718p. 